\title{
MODEL ANALISIS SISTEM PURCHASE ORDER PADA UD. BUDI INDO PERKASA
}

\author{
Andy Santoso ${ }^{1}$, Holong Marisi Simalango² \\ 1,2 Program Studi Teknik Perangkat Lunak, Universitas Universal \\ Kompleks Maha Vihara Duta Maitreya, Kota Batam
}

E-mail : andysantoso54@gmail.com ${ }^{1}$, simalangoholong@gmail.com²

\begin{abstract}
ABSTRAK
Purchase order (PO) merupakan proses ketika staf sales mencatat pesanan barang oleh pihak distribusi yaitu minimarket, supermarket, dan toko yang disesuaikan stok barang gudang. Staf sales menggunakan daftar stok barang yang telah dicetak oleh staf admin untuk mengunjungi tempat distribusi dalam pemeriksaan ketersediaan barang. Staf sales mengirimkan catatan pesanan kepada staf admin menggunakan aplikasi jejaring sosial yaitu LINE. Staf admin mencatat kembali pesanan untuk staf gudang agar menyiapkan barang sesuai pesanan. Analisis susulan sistem PO merupakan analisis model / cara sistem lama, dimana dapat dijadikan sebagai solusi alternatif kekurangan sistem lama. Analisis usulan sistem PO ini berfokus pada beberapa aktor, yaitu staf admin, staf sales, dan staf gudang. Aktor staf admin memiliki hak untuk mengelola data pegawai, mengelola data pelanggan, mencetak laporan, dan mengelolah data barang. Aktor staf sales memiliki hak untuk menampilkan katalog, melihat daftar data barang, dan mengelola PO. Aktor staf gudang memiliki hak untuk melihat laporan PO. Object oriented analysis (OOA) merupakan metodologi yang digunakan untuk melakukan analisis, dan menggunakan unified modeling language (UML) untuk sebagai analisis proses bisnis dan sistem. Hasil dari analisis sistem PO adalah bentuk rekomendasi analisis dan rancangan tampilan antarmuka untuk rancang bangun aplikasi ke tahap selanjutnya. Analisis rancangan arsitektur sistem dan kebutuhan perangkat dengan penerapan tren teknologi yang akan memberi kemudahan dan dukungan kepada staf admin, staf sales, dan staf gudang yang akan menggunakan sistem PO di UD. Budi Indo Perkasa.
\end{abstract}

Kata kunci : Purchase order (PO), object oriented analysis (OOA), unified modeling language $(U M L)$

\section{ABSTRACT}

A purchase order is a process of a sales staff creates the order of the items by the distributors, like minimarkets, supermarkets, and stores, in which the items will be adjusted with the stock of the warehouse. Sales staff uses the list of items stock, which are printed by the admin staff. Sales staff using it to visit the distributor and inspecting the availability of goods. Sales staff sends order notes to admin staff using Line application. The admin staff recreates those orders, which used by the warehouse staff for preparing the items of the orders. The alternative analysis of the PO system is an analysis of the current system, which can be used as an alternative solution for old system deficiencies. That new analysis proposed PO system focuses on several actors, namely admin staff, sales staff, and warehouse staff. The admin staff has access to manage employee data, manage customer data, print reports, and manage item data. The sales staff has access to display the catalog, view the item data list, and manage the PO. The warehouse staff actor 
has access to view PO reports. Object-Oriented Analysis (OOA) is a methodology used to conduct analysis and Unified Modeling Language (UML) for analyzing business processes and systems. The results of the $P O$ system analysis are a form of analysis recommendation and interface design for the application design to the next stage. Analysis of system architecture design and device requirements by applying technology trends that will provide convenience and support to admin staff, sales staff and warehouse staff who will use the PO system at UD. Budi Indo Perkasa.

Keywords : Purchase order (PO), object oriented analysis (OOA), unified modeling language $(U M L)$

\section{PENDAHULUAN}

Perkembangan teknologi informasi banyak bertambah dan berubah pada perangkat keras dan perangkat lunak. Penggunaan perangkat lunak semakin banyak diterapkan di perusahaan berbagai bidang. Menurut Sholeh (2019) bahwa Penerapan teknologi berperan penting terhadap perusahaan untuk mempengaruhi kinerja di beberapa divisi. Penerapan penggunaan perangkat lunak di bidang retail / gudang besar dapat membantu proses antara lain penjualan produk, membuat laporan, melihat stok, mengimput data, mencetak purchase order (PO), dan lain-lain.

Usaha Dagang (UD) Budi Indo Perkasa memiliki bisnis distribusi yaitu memasarkan produk makanan import ke toko, supermarket, dan minimarket. UD. Budi Indo Perkasa memiliki divisi yang terediri dari admin, accounting, sales, gudang, dan supir. UD. Budi Indo Perkasa mendistribusikan coklat dengan merek Sweetkiss, Barnsberry dan menjual kukis dengan merek TYL kepada toko, supermarket, dan minimarket. Pada divisi admin merekam data / memasukkan data barang masuk ke dalam sistem / aplikasi Excel di komputer admin, kemudian mencetak daftar persediaan barang atau stok yang ada di gudang dan memasukkan PO yang dijadikan nota.

Pada sistem yang berjalan admin merekam data barang ke dalam komputer cetak stok barang kepada sales. Sales mengunjungi ke tempat pendistribusian untuk melakukan pengecekan ketersediaan barang, mencatat barang yang akan dipesan yang disesuaikan dengan ketersediaan barang di gudang UD. Budi Indo Perkasa. Sales mendokumentasikan daftar pesanan barang, kemudian mengirimkan dokumentasi ke admin melalui aplikasi kirim pesan yaitu menggunakan aplikasi LINE. Admin mencatat pesanan yang didokumentasi dari sales, kemudian diberikan kepada staf gudang untuk mengambil barang dari gudang dan memindahkan ke tempat barang yang siap kirim. Admin memasukkan data barang sesuai barang yang telah dipisahkan ke dalam sistem PO, kemudian mencetak surat invoice. Admin memverifikasi kembali surat invoice dengan barang yang telah dipisahkan.

Sistem yang sedang berjalan masih menggunakan kertas, misalnya laporan daftar stok barang dan pencatatan daftar pesanan. Pencatatan daftar pesanan dilakukan hanya mendokumentasikan yang dikirimkan melalui aplikasi LINE, akan beresiko jika aplikasi mengalami maintenance seperti yang sering terjadi. Proses menawarkan barang ke outlet baru masih manual, dimana katalog yang masih tidak terdapat gambar atau bahkan menelusuri di Google, dimana proses tersebut mengakibatkan menghabiskan banyak waktu untuk menawarkan barang.

Analisis ini merupakan analisis dari sistem yang sedang berjalan yaitu proses konvensional dan proses yang sudah terkomputerisasi namun masih bisa diusulkan dengan perencanaan untuk alternatif sistem selanjutnya. 


\section{METODOLOGI PENELITIAN DAN TEORI}

Adapun metode penelitian yang digunakan dalam penulisan penelitian ini meliputi :

a. Inisiasi. Menurut Simalango (2019) bahwa tahap inisiasi terdiri dari studi literatur dan diskusi. Studi literatur sering disebut dengan studi kepustakaan yang merupakan memahami konsep teori dan referensi pendukung sebagai pondasi untuk melanjutkan perencanaan perancangan dan metode yang digunakan penelitian ini yang bisa dilihat dari sisi bisnis dan pengembangan sistem yang akan dibangun. Adapun referensi pendukung penelitian yang dipilih yaitu:

1) Menurut Rifai et al. (2011) Rancang bangun aplikasi ini berfokus pada administrasi untuk pencatatan data transaksi, penerimaan barang, pengadaan barang. Aplikasi ini berbasis desktop.

2) Menurut Anwar et al. (2017) Rancang bangun aplikasi ini berfokus pada admin dan sales. Namun website hanya dibuat berbasis tampilan desktop.

3) Menurut Sari (2017) pada perancangan purchase order berfokus kepada persediaan barang agar meminimalis kekosongan barang di rumah sakit ke sales agar dapat mengisi barangnya dengan cepat. Tampilan desain dapat merespon layar ketika memperbesar dan memperkecil tampilan sesuai resolusi.

Diskusi dilakukan untuk pengumpulan data yang dilakukan dengan langsung ke pemilik UD Indo Budi Perkasa beserta stafnya.

b. Sistem Purchase Order (PO). Menurut Nurdin (2018) bahwa Sistem PO adalah permintaan barang yang merupakan dari pembeli ke penjual, kemudian pembeli meminta kepada penjual untuk mengisi stok barang ke toko dalam bentuk dokumen atau berkas. Sistem pada PO adalah pembeli memesan barang ke penjual untuk mengisi stok kembali ataupun dengan adanya permintaan dari konsumen.

c. Object oriented analysis (OOA). merupakan tahap dalam melakukan analisis yang berorientasi objek mencakup representasi kelas dan hirarki kelas, model hubungan perilaku objek.

\section{PEMBAHASAN DAN HASIL}

a. Analisis Sistem Yang Sedang Berjalan

Pada tahap ini melakukan analisis sistem dan bisnis yang sedang berjalan.

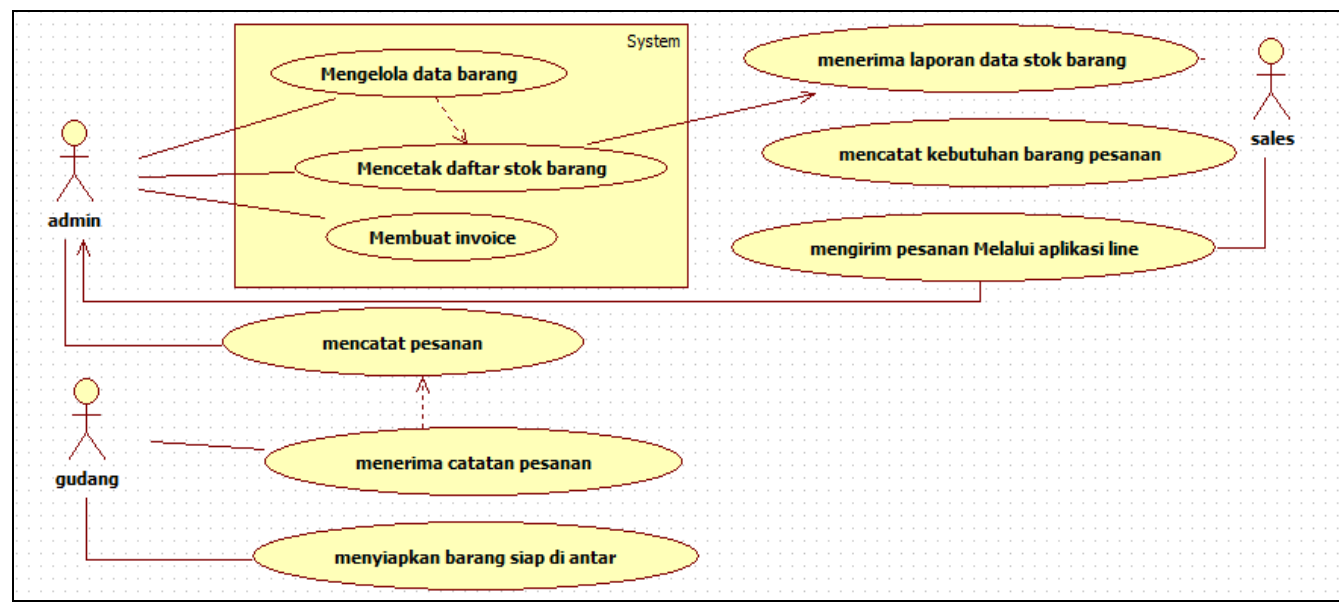

Gambar 1. Usecase diagram sistem dan bisnis yang sedang berjalan 
Pada gambar 1 merupakan usecase diagram sistem dan bisnis yang sedang berjalan yang mempunyai tiga aktor, antara lain:

1) Admin : admin dapat mengelola data barang, mencetak daftar stok barang, membuat invoice dan mencatat pesanan

2) Sales : sales menerima laporan stok barang, mencatat kebutuhan barang pesanan dan mengirim pesanan melalui aplikasi LINE

3) Gudang : menerima catatan pesanan dan menyiapkan barang siap untuk di antar

b. Use Case Diagram Usulan

Use case diagram usulan merupakan analisis dari sistem dan prosedur yang sedang berjalan di UD. Budi Indo Perkasa. Use case diagram usulan yang digambarkan, sebagai berikut:

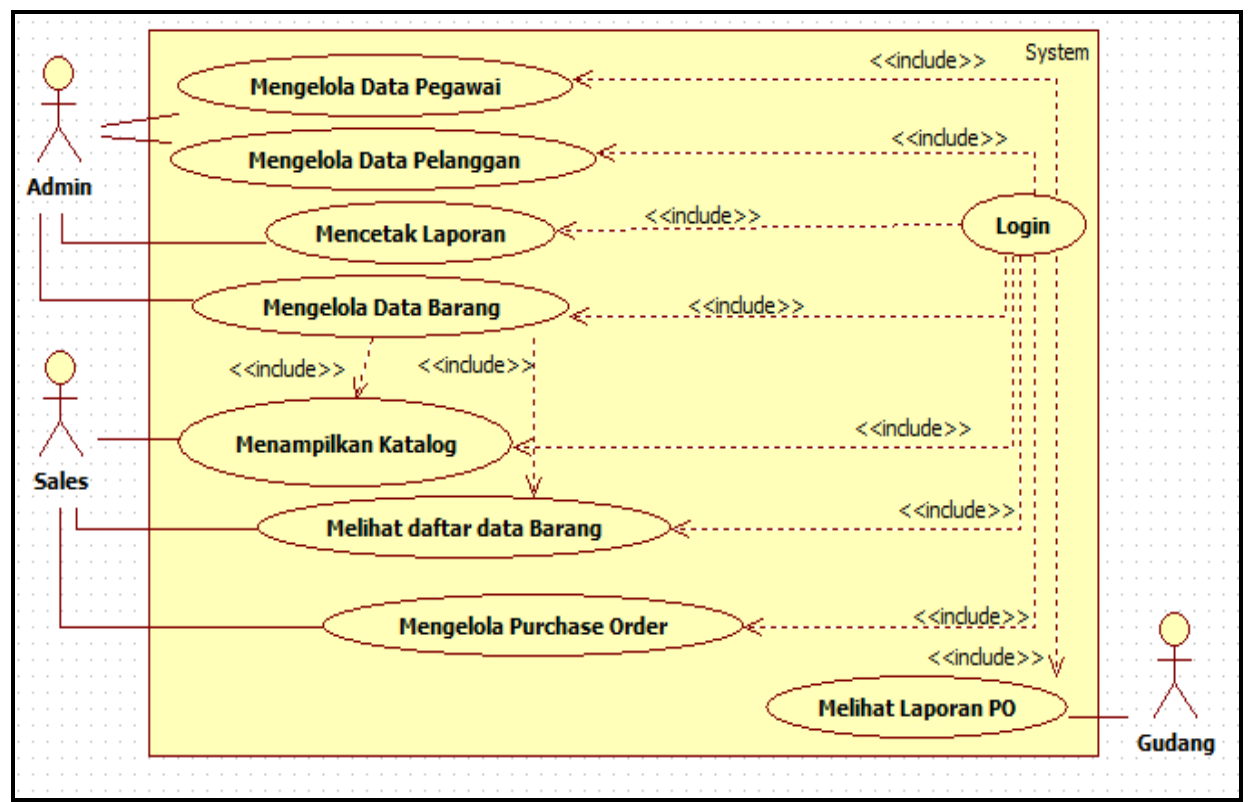

Gambar 2. Use Case Diagram Usulan

Dari gambar 2 terdapat tiga aktor dan fungsinya, antara lain:

1) Admin, orang yang bertugas dan memilikin hak akses melakukan merekap stok barang, memasukan data barang, mengubah data.

2) Sales, orang yang bertugas menginput pesanan dari pelanggan toko, melihat data stok barang, menampilkan katalog

3) Staf Gudang, orang yang hanya melihat dokumentasi pesanan dari sales

Dari gambar 2 juga terdapat berbagai usecase, antara lain :

Tabel 1. Tabel Deskripsi Usecase

\begin{tabular}{|c|l|l|}
\hline No & \multicolumn{1}{|c|}{ Usecase } & \multicolumn{1}{c|}{ Deskripsi } \\
\hline 1 & Login & $\begin{array}{l}\text { Proses dimana aktor dapat mengakses aplikasi dimulai } \\
\text { dari login }\end{array}$ \\
\hline 2 & Mengelola data pegawai & $\begin{array}{l}\text { Proses untuk mengolah data pegawai UD.Budi Indo } \\
\text { Perkasa yaitu proses menambahkan, mengubah, dan } \\
\text { menghapus data }\end{array}$ \\
\hline 3 & Mengelola data Barang & $\begin{array}{l}\text { Proses untuk mengolah data barang yaitu proses } \\
\text { menambahkan, mengubah, dan menghapus data }\end{array}$ \\
\hline 4 & Mengelola data & Proses untuk mengolah data pelanggan yaitu proses \\
\hline
\end{tabular}




\begin{tabular}{|c|l|l|}
\hline No & \multicolumn{1}{|c|}{ Usecase } & \multicolumn{1}{c|}{ Deskripsi } \\
\hline & pelanggan & menambahkan, mengubah, dan menghapus data \\
\hline 5 & Mencetak laporan & Proses untuk mencetak laporan transaksi \\
\hline 6 & Menampilkan katalog & Proses daftar barang dengan tampilan gambar barang \\
\hline 7 & Melihat data barang & Menampilkan stok barang yang tersedia \\
\hline 8 & Mengelola data PO & $\begin{array}{l}\text { Proses untuk mengolah data pesanan barang dari } \\
\text { pembeli yaitu proses menambahkan, mengubah, dan } \\
\text { menghapus data }\end{array}$ \\
\hline 9 & Melihat laporan PO & $\begin{array}{l}\text { Proses hanya untuk melihat daftar pesanan barang } \\
\text { pembeli }\end{array}$ \\
\hline
\end{tabular}

\section{c. Activity Diagram Untuk Mengelola Data Pegawai}

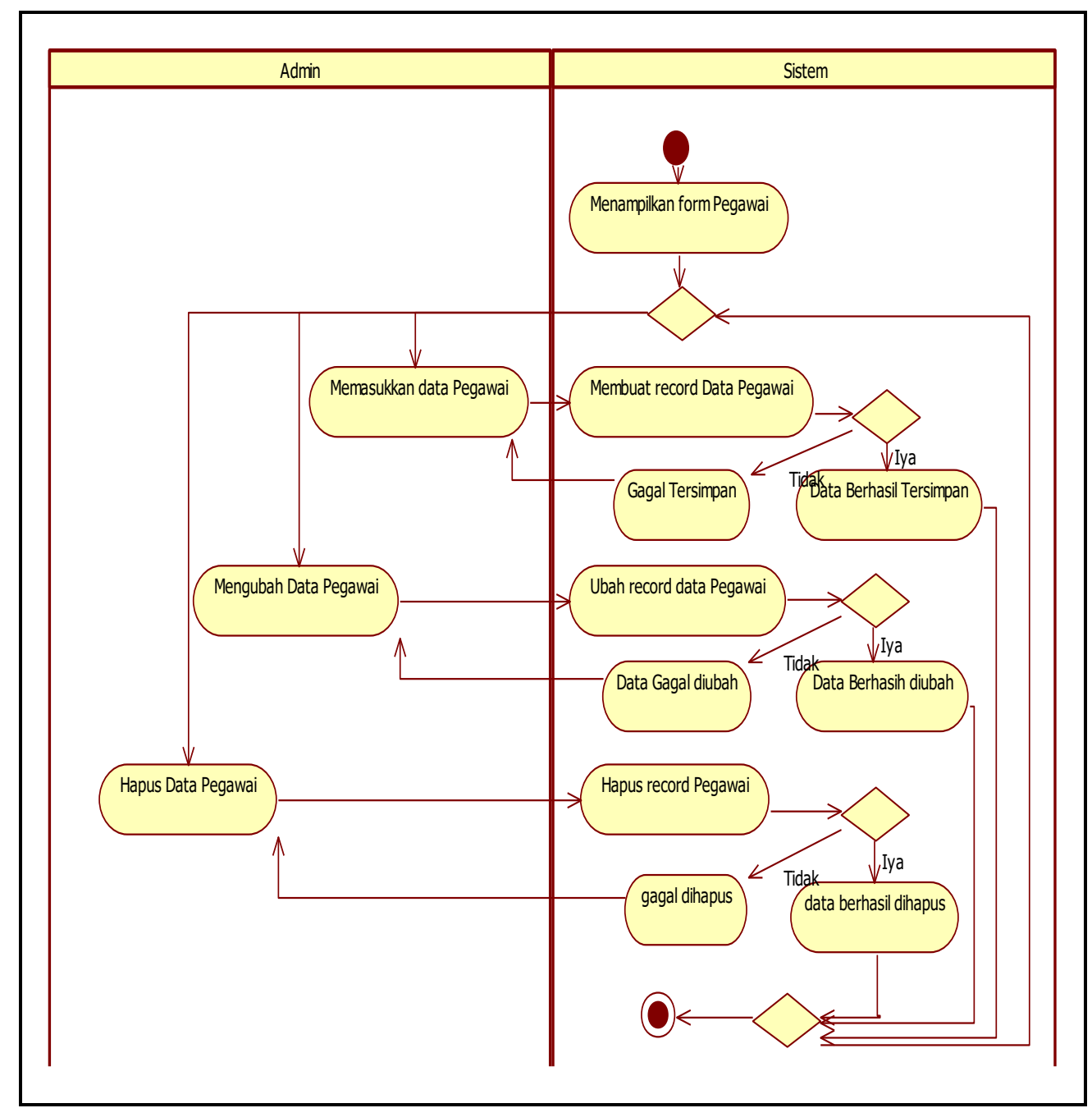

Gambar 3. Activity Diagram Untuk Mengelola Data Pegawai

Pada gambar 3 merupakan activity diagram mengelola data pegawai. Admin menggunakan aplikasi yang menampilkan tampilan kelola data pegawai. Admin memiliki hak, antara lain :

1) Memasukkan data pegawai. Jika proses memasukkan data berhasil maka admin memiliki hak untuk fungsi lainnya. Jika proses memasukkan data gagal, maka admin bisa mengulang kembali memasukkan data, atau membatalkan memasukkan data pegawai.

2) Mengubah data pegawai. Jika proses mengubah data berhasil maka admin memiliki hak untuk fungsi lainnya. Jika proses mengubah data 
gagal, maka admin bisa mengulang kembali mengubah data, atau membatalkan mengubah data pegawai.

3) Menghapus data pegawai. Jika proses menghapus data berhasil maka admin memiliki hak untuk fungsi lainnya. Jika proses menghapus data gagal maka admin bisa mengulang kembali menghapus data, atau membatalkan menghapus data pegawai.

\section{d. Activity Diagram Untuk Mengelola Data Pelanggan}

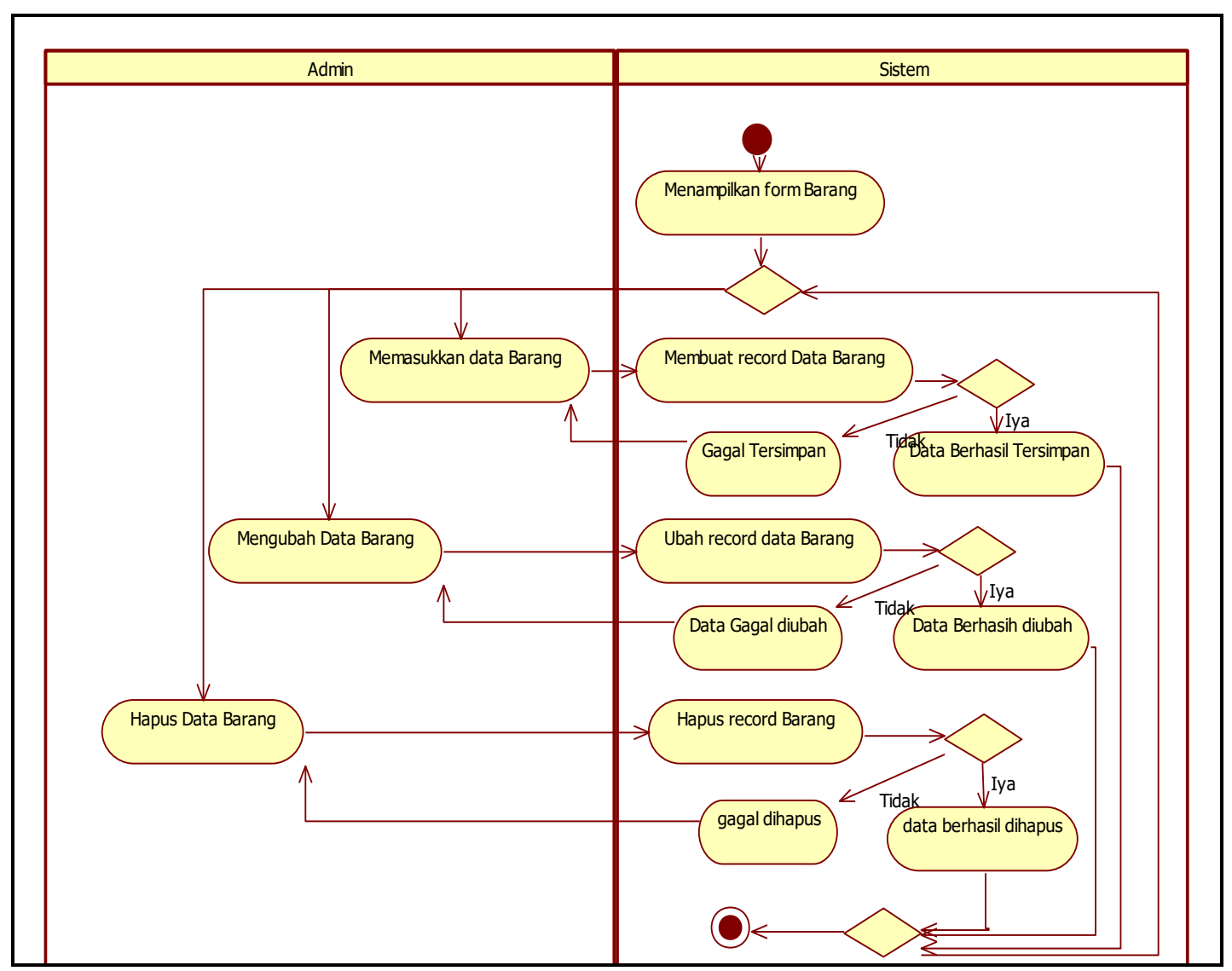

Gambar 4. Activity Diagram Untuk Mengelola Data Pelanggan

Pada gambar 4 merupakan activity diagram mengelola data pelanggan. Admin menggunakan aplikasi yang menampilkan tampilan kelola data pelanggan. Admin memiliki hak, antara lain :

1) Memasukkan data pelanggan. Jika proses memasukkan data berhasil maka admin memiliki hak untuk fungsi lainnya. Jika proses memasukkan data gagal, maka admin bisa mengulang kembali memasukkan data, atau membatalkan memasukkan data pelanggan.

2) Mengubah data pelanggan. Jika proses mengubah data berhasil maka admin memiliki hak untuk fungsi lainnya. Jika proses mengubah data gagal, maka admin bisa mengulang kembali mengubah data, atau membatalkan mengubah data pelanggan.

3) Menghapus data pelanggan. Jika proses menghapus data berhasil maka admin memiliki hak untuk fungsi lainnya. Jika proses menghapus data gagal maka admin bisa mengulang kembali menghapus data, atau membatalkan menghapus data pelanggan. 
e. Activity Diagram Untuk Mengelola Data Barang

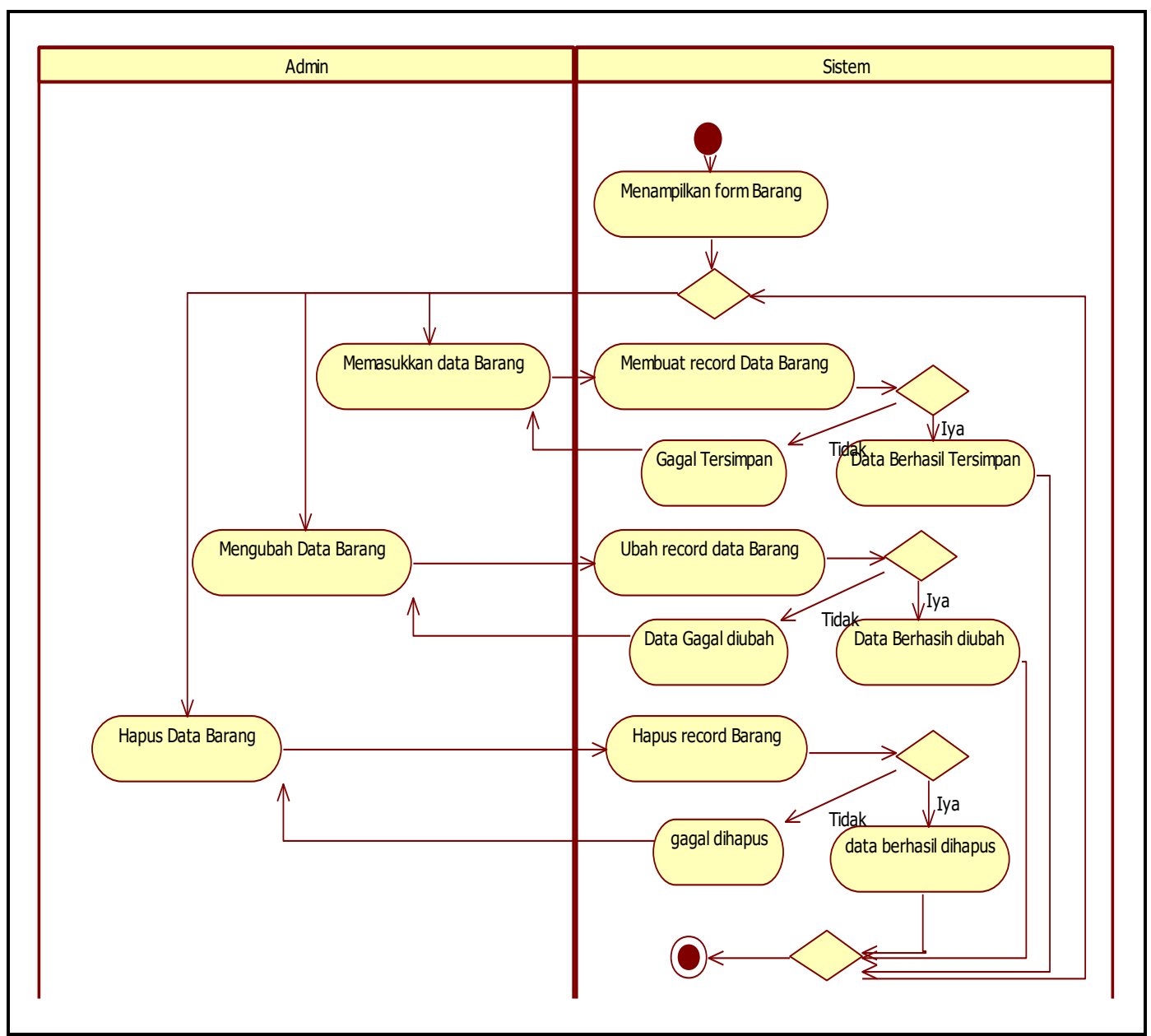

Gambar 5 Activity Diagram Untuk Mengelola Data Barang

Pada gambar 5 merupakan activity diagram untuk mengelola data barang. Admin menggunakan aplikasi yang menampilkan tampilan kelola data barang. Admin memiliki hak, antara lain:

1) Memasukkan data barang. Jika proses memasukkan data berhasil maka admin memiliki hak untuk fungsi lainnya. Jika proses memasukkan data gagal, maka admin bisa mengulang kembali memasukkan data, atau membatalkan memasukkan data barang.

2) Mengubah data barang. Jika proses mengubah data berhasil maka admin memiliki hak untuk fungsi lainnya. Jika proses mengubah data gagal, maka admin bisa mengulang kembali mengubah data, atau membatalkan mengubah data barang.

3) Menghapus data barang. Jika proses menghapus data berhasil maka admin memiliki hak untuk fungsi lainnya. Jika proses menghapus data gagal maka admin bisa mengulang kembali menghapus data, atau membatalkan menghapus data barang. 
f. Activity Diagram Untuk Mencetak Laporan

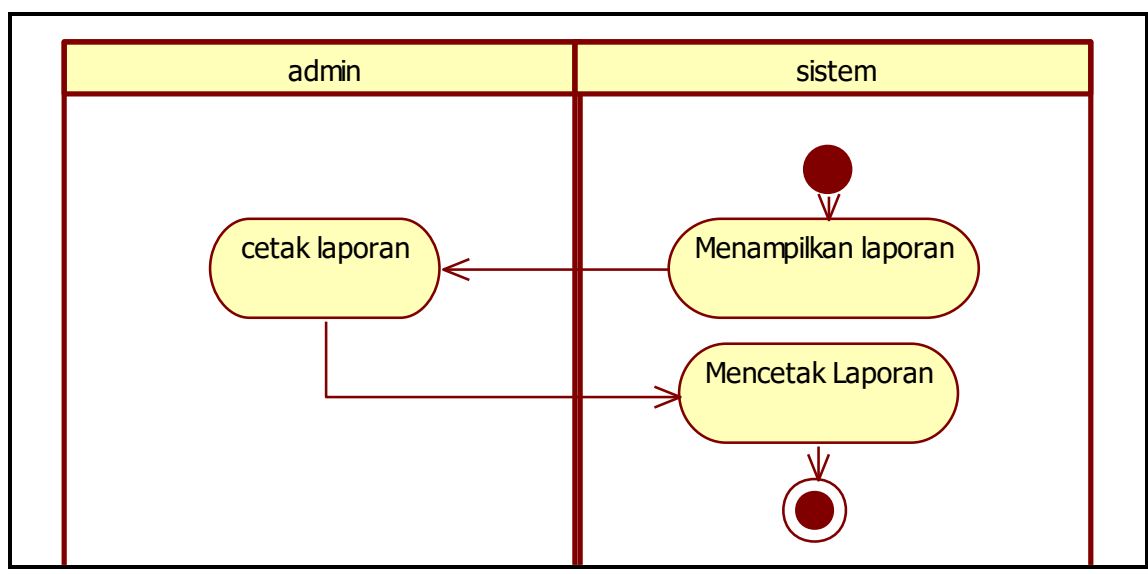

Gambar 6. Activity Diagram Untuk Mencetak Laporan

Pada gambar 6 merupakan activity diagram untuk mencetak laporan. Admin menggunakan aplikasi yang menampilkan tampilan laporan. Admin mencetak laporan.

g. Activity Diagram Untuk Menampilkan Daftar Data Barang

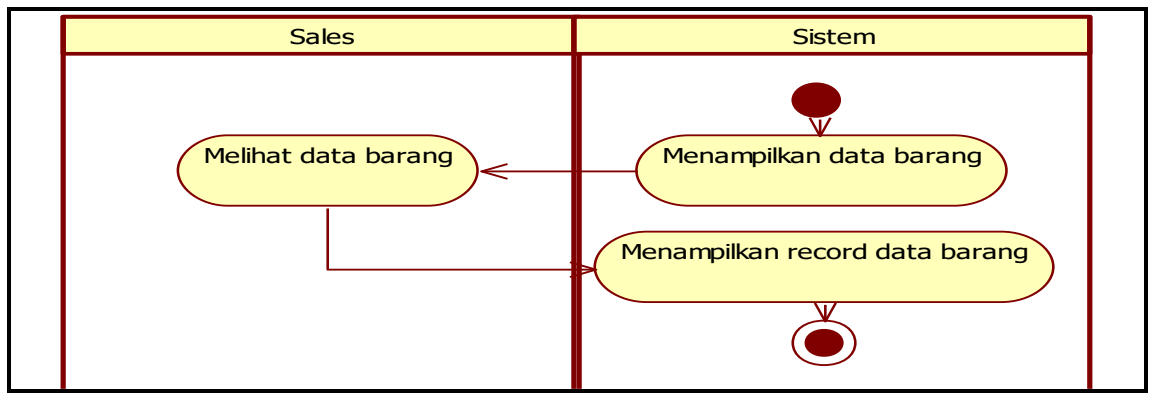

Gambar 7. Activity Diagram untuk menampilkan data barang

Pada gambar 7 merupakan activity diagram menampilkan data barang. sales menggunakan aplikasi yang menampilkan data barang. Sales melihat record data barang

h. Activity Diagram Untuk Menampilkan Katalog

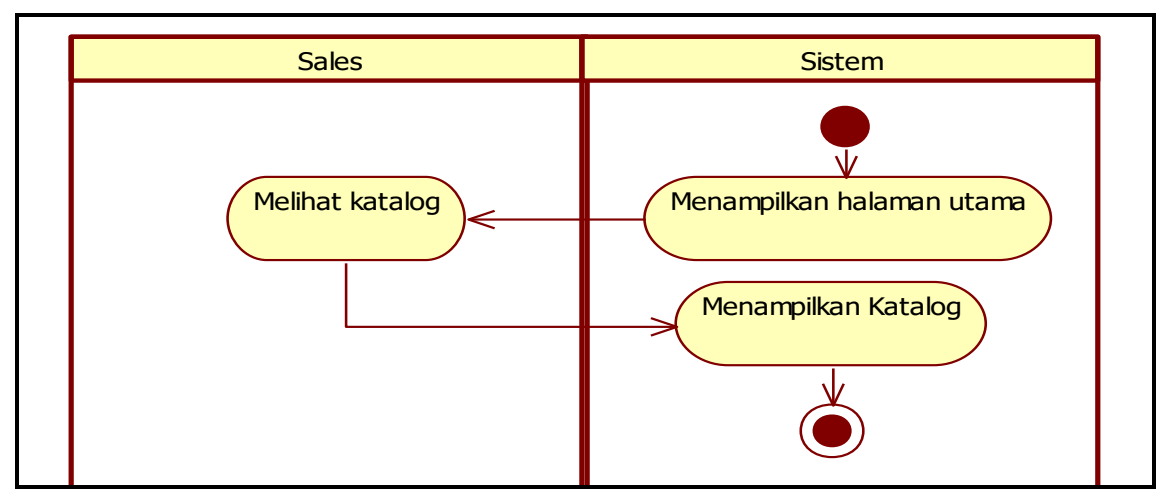

Gambar 8. Activity Diagram Menampilkan Katalog 
Pada gambar 8 merupakan activity diagram menampilkan katalog. sales menggunakan aplikasi yang menampilkan katalog. sales memiliki hak hanya melihat katalog

i. Activity Diagram Untuk Mengelola Purchase Order (PO)

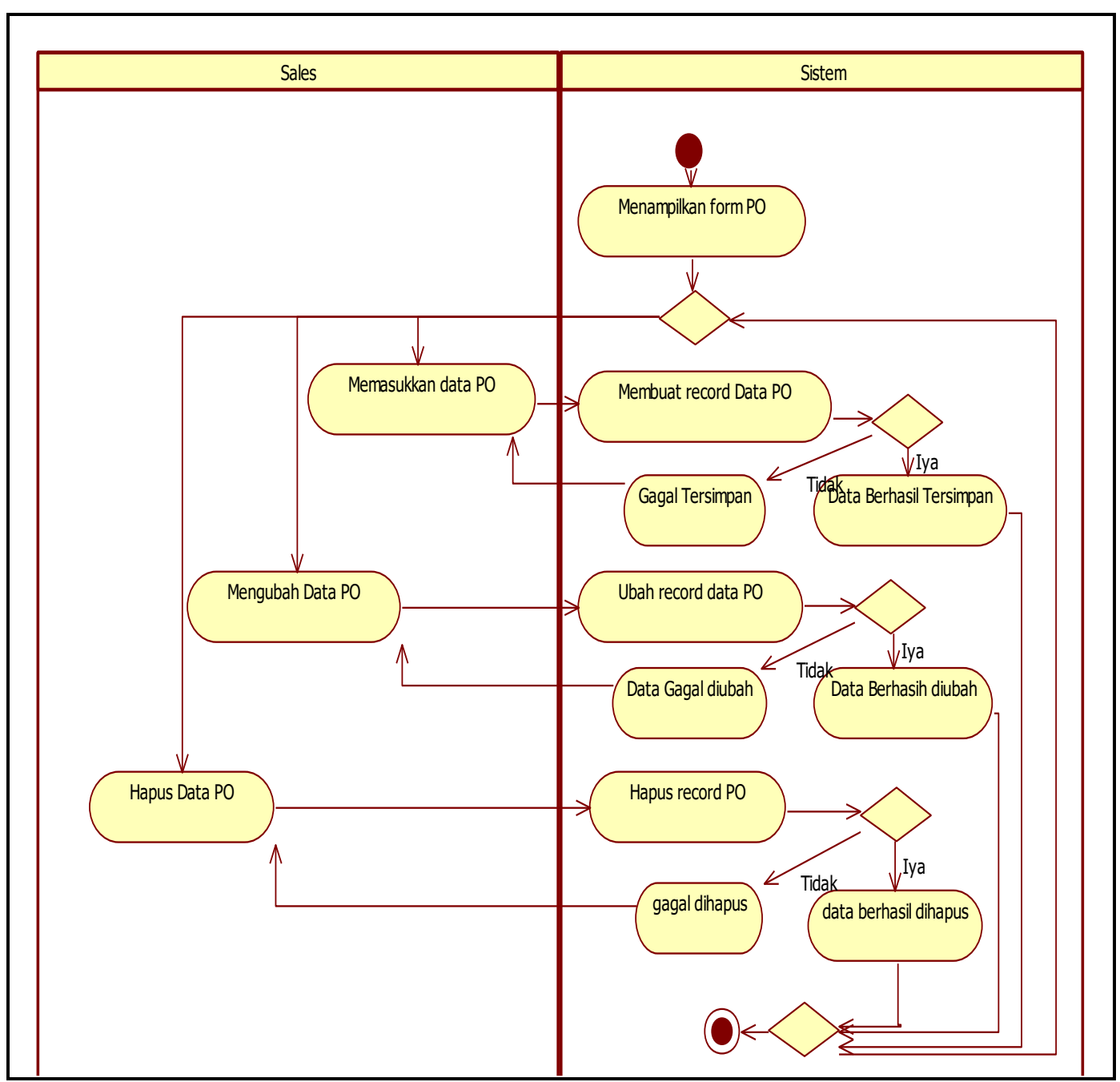

Gambar 9. Activity Diagram untuk Purchase Order

Pada gambar 9 merupakan activity diagram untuk mengelola PO. Sales menggunakan aplikasi yang menampilkan tampilan kelola data PO. Sales memiliki hak, antara lain:

1) Memasukkan data PO. Jika proses memasukkan data berhasil maka sales memiliki hak untuk fungsi lainnya. Jika proses memasukkan data gagal, maka sales bisa mengulang kembali memasukkan data, atau membatalkan memasukkan data PO.

2) Mengubah data PO. Jika proses mengubah data berhasil maka sales memiliki hak untuk fungsi lainnya. Jika proses mengubah data gagal, maka sales bisa mengulang kembali mengubah data, atau membatalkan mengubah data $\mathrm{PO}$.

3) Menghapus data PO. Jika proses menghapus data berhasil maka sales memiliki hak untuk fungsi lainnya. Jika proses menghapus data gagal 
maka sales bisa mengulang kembali menghapus data, atau membatalkan menghapus data PO.

j. Activity Diagram Untuk Melihat Laporan PO

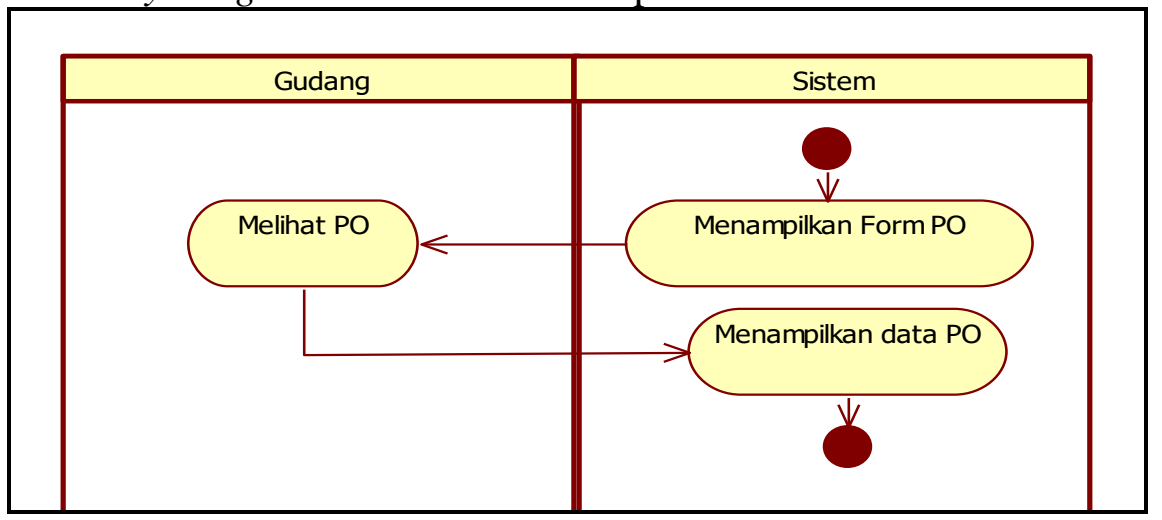

Gambar 10. Activity Diagram Melihat Laporan PO

Pada gambar 10 merupakan activity diagram untuk melihat PO. Gudang menggunakan aplikasi yang menampilkan tampilan PO

\section{k. Class Diagram}

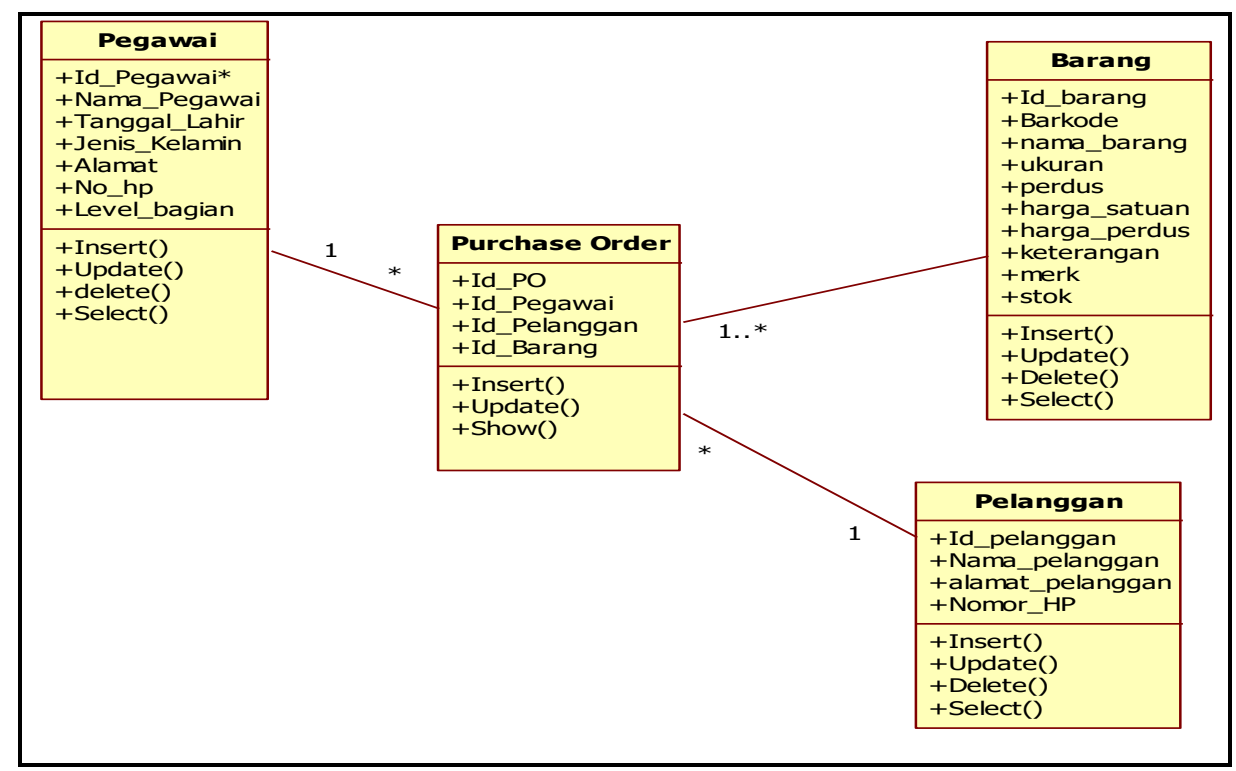

Gambar 11. Class Diagram

Dari gambar 11 merupakan class diagram yang memetakan hubungan antar tabel di database. Clas diagram tersebut terdiri dari:

1) Pegawai Class

2) Purchase Order Class,

3) Barang Class,

4) Pelanggan Class

1. Kebutuhan Perangkat Keras

Kebutuhan perangkat yang dipakai dalam penerapan pengusulan pengembangan sistem ini, antara lain: 
Tabel 2. Kebutuhan Perangkat Keras

\begin{tabular}{|l|l|l|}
\hline No & Kebutuhan & \multicolumn{1}{c|}{ Spesifikasi } \\
\hline 1 & Device & Smartphone, Server, Personal Computer, Laptop \\
\hline 2 & Konektor & Kabel UTP, Router \\
\hline
\end{tabular}

m. Kebutuhan Perangkat Lunak

Kebutuhan perangkat lunak yang dipakai dalam penerapan pengusulan pengembangan sistem ini, antara lain:

Tabel 3. Kebutuhan Perangkat Lunak

\begin{tabular}{|l|l|l|}
\hline No & \multicolumn{1}{|c|}{ Kebutuhan } & \multicolumn{1}{c|}{ Spesifikasi } \\
\hline 1 & Sistem Operasi & Windows 10, Android, iOS \\
\hline 2 & Official IDE & PHP \\
\hline 3 & Database & MySQL \\
\hline 4 & Browser & Mozilla Firefox versi 76, Google Chrome versi 80 \\
\hline 5 & Internet & 20 Mbps \\
\hline
\end{tabular}

n. Rancangan Arsitektur Sistem dan Alat Bantu

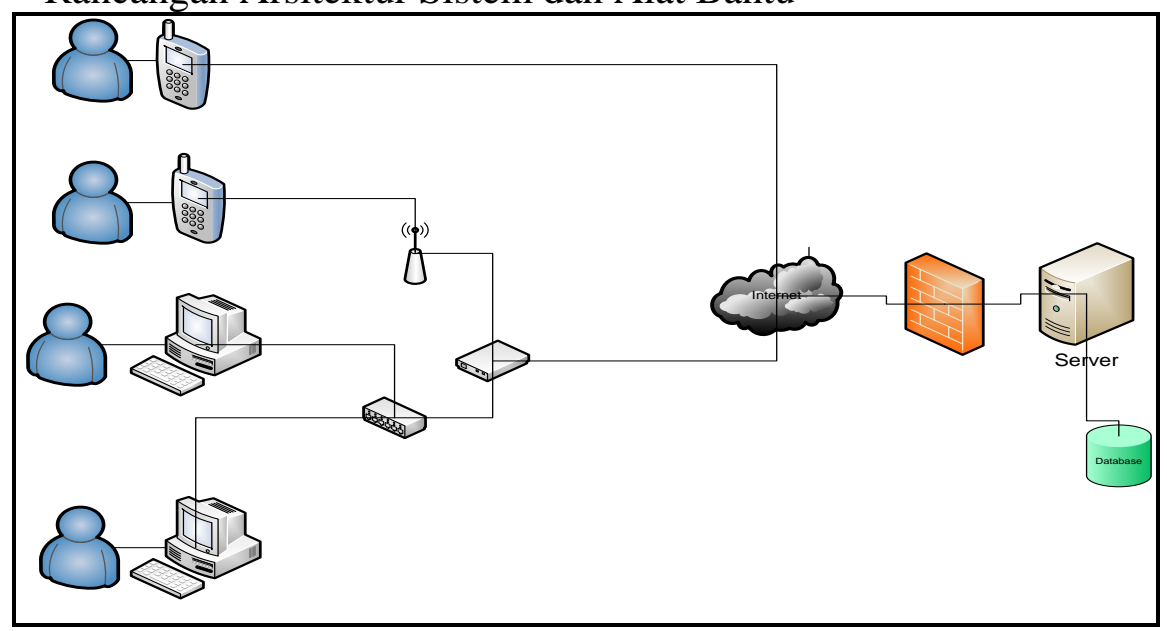

Gambar 12. Rancangan Arsitektur sistem dan alat bantu

Staf admin mengakses sistem PO berbasis web desktop di PC yang ada di UD Budi Indo Perkasa untuk mengelola data pelanggan, pegawai, dan barang. PC terhubung dengan Internet yang menggunaan router dengan kecepatan 20MBps. Data tersebut disimpan di Server dengan keamanan menggunakan firewall. Sales mengakses aplikasi sistem berbasis web mobile PO dengan menggunakan smartphone pribadi untuk mengelola PO, menampilkan data barang, menampilkan katalog. Sistem akan mengakses server secara online.

\section{KESIMPULAN}

Simpulan yang didapat dari pengerjaan penelitian ini yaitu analisis sistem PO di UD Budi Indo Perkasa dapat dijadikan rekomendasi dalam rancang bangun sistem PO. Analisis sistem ini digambarkan dengan menggunakan use case diagram, class diagram, dan activity diagram. Analisis sistem ini dideskripsikan untuk digunakan oleh staf admin, staf sales, dan staf Gudang. Konsep dari analisis Sistem PO juga menggambarkan rancangan arsitektur dari sistem dan alat bantu.

Saran yang dapat didapat dari hasil penelitian ini yaitu ketepatan hasil dari analisis usulan Sistem PO tergantung dari pemahaman pengembangkan selanjutnya. Analisis Sistem PO ini direkomendasikan dirancang bangun dengan berbasis web untuk desktop 
dan mobile. Bahasa pemrograman dan ataupun databasenya bisa disesuaikan dengan kebutuhan di lapangan dikemudian hari.

\section{DAFTAR PUSTAKA}

[1] R. Sholeh and K. Huda, "Pengaruh Kemajuan Teknologi Terhadap Volume Pejualan Ritel Di Kota Mojokerto," Optima, vol. 3, no. 1, 2019, doi: 10.33366/optima.v3i1.1253.

[2] H. M. Simalango, M. Khaerul, and N. Mursalim, "Model Arsitektur Smart Library di Perguruan Tinggi Se-Kota Batam," vol. 3, no. 2, pp. 80-83, 2019, [Online]. Available: https://jurnal.polibatam.ac.id/index.php/JAIC/article/view/1672.

[3] A. Rifai, R. Sarno, and D. Sunaryono, "Rancang Bangun Sistem Persediaan (Inventory) Dengan Model Software As a Service Menggunakan Service Oriented Architecture," vol. 3, pp. 1-6, 2011, [Online]. Available:https://pdfs.semanticscholar.org/9b07/4dea3dfd6009daa13a4e69db57b43 24e16ca.pdf.

[4] S. Anwar and F. Irawan, "Rancang Bangun Sistem Informasi Pengajuan Pengadaan Suku Cadang Mobil Pada Pt. Andalan Chrisdeco Berbasis Web," None, vol. 13, no. 1, pp. 113-121, 2017, [Online]. Available: http://ejournal.nusamandiri.ac.id/index.php/pilar/article/view/154.

[5] S. Sari, "Order Pada Apotik Berdasarkan Transaksi," 2017, [Online]. Available: http://repositori.uin-alauddin.ac.id/3834/.

[6] M. Nurdin, "PERANCANGAN SISTEM INFORMASI PURCHASE ORDER BARANG MENGGUNAKAN FORECASTING PADA TOKO GROSIR ( Studi Kasus : Toko Grosir Hidayah ) BARANG MENGGUNAKAN FORECASTING PADA TOKO GROSIR ( Studi Kasus : Toko Grosir Hidayah ),” 2018, [Online]. Available: https://dspace.uii.ac.id/bitstream/handle/123456789/12523/13523173Muhamad Nurdin-Laporan Skripsi.pdf?sequence=1. 